\title{
LEI MARIA DA PENHA - VIOLÊNCIA DOMÉSTICA E FAMILIAR : 12 ANOS DE PROTEÇÃO E EMPODERAMENTO FEMININO
}

Roberta Micheli de Oliveira Cavalcante.

Universidade do Oeste Paulista - UNOESTE, Curso de Direito, Presidente Prudente, SP. E-mail: robertinhamo@hotmail.com

\section{RESUMO}

A lei que rege a tratativa quanto à proteção da mulher é a Lei no 11.340 , de 7 de agosto de 2006, mais conhecida como Lei Maria da Penha. Crescente a cada dia, o assunto é tema dos principais grupos sociais e, dentro da família, é um assunto extremamente delicado, pois envolve diversas questões religiosas, sociais e psicológicas. Mas essa não é a justificativa para que ainda aconteça a violência no lar, necessário ainda muito debate sobre o tema para o fortalecimento e empoderamento da mulher frente a seu agressor.

Palavras chaves: Lei Maria da Penha, Violência doméstica, Mulher, Família, Empoderamento.

\section{ABSTRACT}

The law governing the dealings concerning the protection of women is Law $\mathrm{n}-11.340$, of August 7, 2006, better known as Maria da Penha Law. Growing every day, it is the subject of the main social groups and within the family, is an extremely delicate matter as it involves various religious, social and psychological issues. But this is the justification for which has not happen to violence in the home, must still much debate on the issue for the strengthening and empowerment of front woman to her attacker .

Keywords: Maria da Penha Law, Domestic Violence, Women, Family, Empowerment. 


\section{INTRODUÇÃO}

A violência doméstica e familiar contra as mulheres ocorre em todo o mundo e em diferentes classes sociais. Vista como um sério problema de saúde pública é um tema relevante que ainda precisa ser objeto de muitas discussões. Apesar de grave violação de direitos humanos, a violência doméstica e familiar contra as mulheres segue vitimando milhares de brasileiras. Inúmeras mulheres em situação de violência doméstica e familiar sofrem agressões diariamente, mas muitas dessas se calam seja por medo, desamparo financeiro e emocional.

Portanto, o objetivo deste artigo é a orientação às vítimas de violência doméstica e familiar: seja ela violência física, psicológica, moral, patrimonial ou sexual praticadas por seus companheiros ou ex companheiros.

\section{METODOLOGIA}

O estudo apresenta a metodologia com base no impacto sobre a sociedade diante do tema violência doméstica, com método dedutivo sobre o funcionamento social e administrativo do poder público e entidades responsáveis, com relação à lei em tela e suas medidas protetivas, além de pesquisa bibliográfica no que diz respeito às leis e regulamentos.

\section{RESULTADO}

No sentido de ampliar os espaços de direito a ter direitos, as políticas públicas encontram um enorme desafio. No enfrentamento à violência contra a mulher houve a implantação do CREAS - Centro de Referência Especializado da Assistência Social, cujo foco é a mulher, vítima de violência doméstica e familiar, e sua família, atuando para sua proteção.

$\mathrm{O}$ atendimento de tal equipamento, segundo a NOB-RH/SUAS - norma operacional básica de recursos humanos do sistema único da assistência social, deve operar com profissionais capacitados no atendimento às violências, o CREAS possui técnicos nas áreas de serviço social, psicologia, jurídica e pedagogia para auxiliar os usuários do equipamento ao fortalecimento pessoal, familiar e enfrentamento às violências, especialmente, a violência doméstica e familiar contra a mulher.

Apesar da implementação de políticas públicas nos municípios no escopo de reduzir a violência doméstica e familiar, vê-se a precariedade nos resultados ao enfrentamento da violência doméstica e familiar em razão da dificuldade do acompanhamento das mulheres vítimas pois, depara-se, ainda, com uma grande resistência de tais mulheres em procurar a delegacia de polícia ou mesmo o equipamento CREAS por vergonha ou receio que seus maridos, companheiros etc (os agressores) continuem a agredi-las após a busca de condições de fortalecimento para sair da situação de violência.

Mesmo com a divulgação da Lei Maria da Penha, no intuito da redução da violência doméstica e familiar, muito ainda há que se realizar.

\section{DISCUSSÃO}

Um dos instrumentos mais importantes para o enfrentamento da violência doméstica e familiar contra as mulheres é a Lei Maria da Penha - Lei no 11.340/2006. Esta lei, além de definir e tipificar as formas de violência contra as mulheres (física, psicológica, sexual, patrimonial e moral), também prevê a criação de serviços especializados, como os que integram a rede de enfrentamento à violência contra a mulher, compostos por instituições de segurança pública, justiça, saúde e da assistência social.

A Lei Maria da Penha - Lei no 11.340/2006 é vista como uma marcante conquista na luta em face da violência doméstica e familiar que vitimiza milhares de mulheres.

Maria da Penha Maia Fernandes é uma farmacêutico-bioquímica, cearense, que foi 
vítima de duas tentativas de homicídio por parte de seu então marido. Passados quase 20 anos, o agressor ainda não havia sido julgado e poderia se beneficiar da prescrição. Com o apoio de organizações de direitos humanos, Maria da Penha, em parceria com o Centro pela Justiça pelo Direito Internacional (CEJIL) e o Comitê Latino-Americano de Defesa dos Direitos da Mulher (CLADEM), denunciou a omissão do Estado brasileiro junto à Comissão de Direitos Humanos da Organização dos Estados Americanos (OEA).

Por meio do relatório n. 54/2001, a Comissão de Direitos Humanos da Organização dos Estados Americanos (OEA), reconheceu a omissão do Estado brasileiro, por não atender ao artigo 70 a Convenção de Belém do Pará, que determina o compromisso de os Estados Partes empenharem-se em:

a. Abster-se de qualquer ação ou prática de violência contra a mulher e velar para que as autoridades, seus funcionários, pessoal e agentes e instituições públicas se comportem conforme esta obrigação; $b$. Atuar com a devida diligência para prevenir, investigar e punir a violência contra a mulher; $c$. incluir em sua legislação interna normas penais, civis e administrativas, assim como as de outra natureza que sejam necessárias para prevenir, punir e erradicar a violência contra a mulher e adotar as medidas administrativas apropriadas que venham ao caso; $d$. adotar medidas jurídicas que exijam do agressor abster-se de fustigar, perseguir, intimidar, ameaçar, machucar ou pôr em perigo a vida da mulher de qualquer forma que atente contra sua integridade ou prejudique sua propriedade; e. Tomar todas as medidas apropriadas, incluindo medidas de tipo legislativo, para modificar ou abolir leis e regulamentos vigentes, ou para modificar práticas Jurídicas e consuetudinárias que respaldem a persistência ou tolerância da violência contra a mulher; f. estabelecer procedimentos jurídicos justos e eficazes para a mulher que tenha sido submetida à violência, que incluam, entre outros, medidas de proteção, um julgamento oportuno e o acesso efetivo a tais procedimentos; g. Estabelecer os mecanismos judiciais e administrativos necessários para assegurar que a mulher objeto de violência tenha acesso efetivo a ressarcimento, reparação do dano ou outros meios de compensação justos e eficazes; e $h$. adotar as disposições legislativas ou de outra índole que sejam necessárias para efetivar esta Convenção.

Baseou-se também na violação dos artigos 1으, 8으 e 25으 da Convenção Americana dos Direitos Humanos, que dispõem sobre a obrigação dos Estados Partes respeitarem os direitos, garantias judiciais e proteção judicial.

Deste modo, essa Comissão reconheceu a grave omissão e recomendou ao Estado brasileiro celeridade e efetividade na conclusão do processamento penal do agressor, indenizar Maria da Penha e promover processo de reforma que evite a tolerância estatal e o tratamento discriminatório com respeito à violência doméstica contra mulheres no Brasil.

Diante disso, o governo federal brasileiro sancionou a Lei $11.340 / 2006$, dando-lhe o nome de Lei Maria da Penha em homenagem a essa corajosa mulher brasileira.

Esta Lei cria mecanismos para coibir e prevenir a violência doméstica e familiar contra a mulher e estabelece medidas de assistência e proteção às mulheres em situação de violência doméstica e familiar.

A Lei 11.340/2006, assim dispõe:

Art. 1o Esta Lei cria mecanismos para coibir e prevenir a violência doméstica e familiar contra a mulher, nos termos do $\S 80$ do art. 226 da Constituição Federal, da Convenção sobre a Eliminação de Todas as Formas de Violência contra a Mulher, da Convenção Interamericana para Prevenir, Punir e Erradicar a Violência contra a Mulher e de outros tratados internacionais ratificados pela República Federativa do Brasil; dispõe sobre a criação dos Juizados de Violência Doméstica e Familiar contra a Mulher; e estabelece medidas de assistência e proteção às mulheres em situação de violência doméstica e familiar. 
Embora exista a lei e muitas campanhas tentando inibir a violência doméstica, ela ainda representa um percentual muito grande tanto nas pequenas quanto nas grandes cidades.

A Lei Maria da Penha, neste ano de 2018, completou doze anos de existência e tem como finalidade proporcionar instrumentos que possam coibir prevenir e erradicar a violência doméstica e familiar contra a mulher, garantindo sua integridade física, psíquica, sexual, moral e financeiro-patrimonial.

O serviço de natureza sócio assistencial realizado pelo CREAS, através da tipificação nacional dos serviços socioassistenciais - Resolução 109/2009 do MDS, prevê o acompanhamento às famílias em situação de ameaça ou violação de direitos por meio de vigilância social, encaminhamento dos sistemas de políticas e segurança pública e, também, pela demanda espontânea. Compreende orientação e, o atendimento é com base em situações que necessitam de maior atenção, sejam elas por potencial ameaça, ou valores que denigrem suas crenças e identidade familiar. Contribui, portanto, no fortalecimento, integração, proteção e prevenção dos direitos.

Nesse sentido, a delegacia de polícia, seja ela especializada no atendimento à mulher ou não, é, normalmente, onde a vítima de violência doméstica deverá procurar para a queixa e solicitar as medidas protetivas elencadas pela Lei Maria da Penha que serão concedidas judicialmente.

O CREAS, conforme tipificação nacional dos serviços socioassistenciais, é equipamento preparado para o atendimento de várias violências, dentre elas, ao atendimento da violência doméstica e familiar tanto na orientação e acompanhamento da vítima quanto no acolhimento da família.

Verifica-se a necessidade de um trabalho em conjunto com a delegacia de polícia e o CREAS no intuito de atendimento, esclarecimento de direitos e fortalecimento da vítima que normalmente desprovida de autoestima e, amedrontada, se cala.

Necessário destacar que a violência doméstica não distingue idade, classe social, grau de instrução, raça, renda, conforme art. 20 da lei em questão. Vejamos:

Toda mulher, independentemente de classe, raça, etnia, orientação sexual, renda, cultura, nível educacional, idade e religião, goza dos direitos fundamentais inerentes à pessoa humana, sendo-Ihe asseguradas as oportunidades e facilidades para viver sem violência, preservar sua saúde física e mental e seu aperfeiçoamento moral, intelectual e social

Qualquer ação ou omissão baseada no gênero que lhe cause morte, lesão, sofrimento físico, sexual ou psicológico e dano moral ou patrimonial configura-se violência doméstica. (Art. 5ㅇ, LMP)

Por unidade doméstica se entende como o espaço de convívio permanente de pessoas, inclusive as esporadicamente agregadas; e, por âmbito familiar compreende-se a comunidade formada por indivíduos que são ou se consideram aparentados, unidos por laços naturais, por afinidade ou por vontade expressa.

\section{CONCLUSÃO}

A Lei Maria da Penha não tem conteúdo penal mas de mecanismos para coibir a violência doméstica e familiar. Assim, através do CREAS é realizado um trabalho social de enfrentamento a tal violência de gênero onde, além do fortalecimento da vítima e familiares através de realização de grupos de apoio, há ações pontuais para desmistificar a cultura sobre a violência doméstica e familiar através da divulgação da lei. 
Restou comprovado que é fundamental o fortalecimento e empoderamento da mulher que foi, de alguma forma, agredida. Verificou-se que as agressões decorrentes da violência doméstica e familiar atinge todas as classes sociais, que, em sua maioria, o agressor possui algum vício (drogadição ou alcoolismo). Constatou-se, por fim, que apesar de grande parcela da população ter conhecimento sobre a Lei Maria da Penha, necessário, ainda se faz maior divulgação, o que tornará possível que a própria população tenha alertas sobre os prováveis casos. Fica o alerta: em briga de marido (leia-se agressor) e mulher (leia-se vítima) hoje se mete a colher! Denuncie! Disque 180 !

\section{REFERÊNCIAS}

BRASIL. Constituição Federal de 1988.

BRASIL. Lei no 11.340/2006.

CAMPOS, Amini Haddad e CORRÊA, Lindinalva Rodrigues. Direitos Humanos das Mulheres. Curitiba: Juruá, 2007.

CREAS, Alvares Machado/SP.

CUNHA, Rogério Sanches; PINTO, Ronaldo Batista. Violência Doméstica. Lei Maria da Penha (Lei 11.340/2006) Comentada artigo por artigo. São Paulo: RT, 2008.

HERMANN, Leda Maria. Maria da Penha: lei com nome de mulher: violência doméstica e familiar, considerações à lei n. 11.340-2006, comentada artigo por artigo. Campinas: Servanda, 2007.

TELES, Maria Amélia de Almeida; MELO, Mônica de. O que é violência contra a mulher? São Paulo: Brasiliense, 2002.

. LEI MARIA DA PENHA. Lei N. ${ }^{\circ} 11.340$, de 7 de Agosto de 2006.

- MINISTÉRIO dO DESENVOLVIMENTO SOCIAL E COMBATE À FOME/SECRETARIA NACIONAL DE ASSISTÊNCIA SOCIAL. CENTRO DE REFERÊNCIA ESPECIALIZADO DE ASSISTÊNCIA SOCIAL - CREAS. Guia de orientação. N. ${ }^{\circ 1}$ 1, 1a versão, Brasília: MDS/SAS, 2007. 
http://www.mariadapenha.org.br/

http://www.quemamaabraca.org.br/2011/index.php/dados-e-informacoes.html 